\title{
Control region mutations and the 'common deletion' are frequent in the mitochondrial DNA of patients with esophageal squamous cell carcinoma
}

\author{
Christian C Abnet*1, Konrad Huppi ${ }^{1}$, Ana Carrera ${ }^{2}$, David Armistead ${ }^{2}$, \\ Keith McKenney ${ }^{2}$, Nan $\mathrm{Hu}^{1}$, Ze-Zong Tang ${ }^{3}$, Philip R Taylor ${ }^{1}$ and \\ Sanford M Dawsey ${ }^{1}$
}

\begin{abstract}
Address: ${ }^{1}$ Cancer Prevention Studies Branch, Center for Cancer Research, National Cancer Institute, Bethesda, MD 20892, USA, ${ }^{2}$ Clearant, Inc., 401 Professional Drive, Gaithersburg, MD 20897, USA and 35hanxi Cancer Hospital, Taiyuan, Shanxi Province, 030013, People's Republic of China

Email: Christian C Abnet* - abnetc@mail.nih.gov; Konrad Huppi - kh2k@nih.gov; Ana Carrera - Carreraj@appliedbiosystems.com; David Armistead - darmistead@clearant.com; Keith McKenney - kmckenney@clearant.com; Nan Hu - nhu@mail.nih.gov; Ze-

Zong Tang - nhu@mail.nih.gov; Philip R Taylor - ptaylor@mail.nih.gov; Sanford M Dawsey - dawseys@mail.nih.gov

* Corresponding author
\end{abstract}

Published: 01 July 2004

BMC Cancer 2004, 4:30 doi:10.1 186/147|-2407-4-30

This article is available from: http://www.biomedcentral.com/I47/-2407/4/30

(c) 2004 Abnet et al; licensee BioMed Central Ltd. This is an Open Access article: verbatim copying and redistribution of this article are permitted in all media for any purpose, provided this notice is preserved along with the article's original URL.
Received: 06 November 2003

Accepted: 0 I July 2004

\begin{abstract}
Background: North central China has some of the highest rates of esophageal squamous cell carcinoma in the world with cumulative mortality surpassing $20 \%$. Mitochondrial DNA (mtDNA) accumulates more mutations than nuclear DNA and because of its high abundance has been proposed as a early detection device for subjects with cancer at various sites. We wished to examine the prevalence of mtDNA mutation and polymorphism in subjects from this high risk area of China.
\end{abstract}

Methods: We used DNA samples isolated from tumors, adjacent normal esophageal tissue, and blood from 21 esophageal squamous cell carcinoma cases and DNA isolated from blood from 23 healthy persons. We completely sequenced the control region (D-Loop) from each of these samples and used a PCR assay to assess the presence of the 4977 bp common deletion.

Results: Direct DNA sequencing revealed that $7 / 21$ (33\%, $95 \% \mathrm{Cl}=17-55 \%)$ tumor samples had mutations in the control region, with clustering evident in the hyper-variable segment I (HSVI) and the homopolymeric stretch surrounding position 309. The number of mutations per subject ranged from I to 16 and there were a number of instances of heteroplasmy. We detected the $4977 \mathrm{bp}$ 'common deletion' in $92 \%$ of the tumor and adjacent normal esophageal tissue samples examined, whereas no evidence of the common deletion was found in corresponding peripheral blood samples.

Conclusions: Control region mutations were insufficiently common to warrant attempts to develop mtDNA mutation screening as a clinical test for ESCC. The common deletion was highly prevalent in the esophageal tissue of cancer cases but absent from peripheral blood. The potential utility of the common deletion in an early detection system will be pursued in further studies. 


\section{Background}

The population of north central China is at very high risk for ESCC with age standardized incidence rates $>125 / 100$ 000 per year [1]. Cumulative mortality attributed to esophageal cancer is approximately $20 \%$ for women and $25 \%$ for men. The cause of these extraordinary rates remains unknown, but previous studies suggest that age, family history $[2,3]$, selenium deficiency [4], and tooth loss [5] are associated with higher risk of esophageal cancer in this population. Tobacco and alcohol use, the leading risk factors for ESCC in Western countries, have only a minor role in this population [6].

Typically, there are 100-1000 mitochondria per cell and each mitochondrion carries 1-10 copies of the mitochondrial genome. Thus there are 100-10,000 times as many mtDNA genomes as there are nuclear genomes per cell. The mitochondrion can repair DNA damage through base excision repair but lacks nucleotide excision repair [7]. Mitochondrial DNA is not protected by histones and the energy generating capacity of the mitochondrion produces high levels of potentially damaging reactive oxygen. Therefore, the higher abundance of mtDNA, the reduced DNA protection, and the limited DNA repair capacity make mtDNA a potentially useful sensor for cellular DNA damage and marker for development of cancer whether these mutations are implicated in the disease process or not.

Mitochondrial DNA from solid tumors or hematologic malignancies often carries acquired alterations [8]. The detection of mutated mtDNA in body fluids [9] and fine needle aspirates [10] suggests that these changes could serve as disease markers. Somatic mtDNA mutations have been found in colorectal, head and neck, esophageal, gastric, bladder, ovarian, and breast cancers among others. Many of the detected changes occur within the non-coding control region (CR; also known as the D-loop) of the mitochondrial genome. A study of ovarian cancer found that $60 \%$ of tumors had at least one mtDNA mutation, with $33 \%$ of the mutations in the CR [11]. In one recent breast cancer study, $74 \%$ of tumor samples had at least one acquired mutation and $81 \%$ of the mutations identified were within the CR, demonstrating that this region of the mitochondrial genome is much more susceptible to mutation than the coding region [12].

In addition to alterations in the $\mathrm{CR}$, several studies have examined the 4977 bp 'common deletion' of the mitochondrial genome in cancer and in degenerative diseases. This somatic mutation appears to accumulate with age, in tumors, and in tissue under other forms of stress, such as liver cirrhosis [13]. A study of gastric cancer demonstrated that 26/32 (81\%) of gastric tumors harbored either a CR alteration or the common deletion in tumor tissue mtDNA [14].

A single case-series has examined mitochondrial DNA alterations in ESCC [15]. This study was conducted in Japan, a population at moderate risk for ESCC. The authors reported that only $2 / 37(5 \%)$ of ESCC tumors harbored CR mutations. In contrast, a recent analysis restricted to the two hypervariable regions of the D-loop found that $13 / 38(34 \%)$ of ESCC tumors in a Japanese series had acquired mutations [16]. A study of esophageal adenocarcinoma in Germany found 8/20 (40\%) had CR alterations in the tumor or tumor-associated Barrett's epithelium [17]. Esophageal adenocarcinoma has a distinct etiology and is primarily thought to result from reflux of stomach or duodenal contents into the esophagus [18]. No published studies have examined the common deletion in esophageal cancer tissue.

\section{Methods}

To determine the frequency of $\mathrm{CR}$ alterations and the 4977 bp common deletion in ESCC, we examined mtDNAs of tumor and adjacent endoscopically normal esophageal tissues and blood from 21 ESCC cases accrued at Shanxi Cancer Hospital in Taiyuan, Shanxi Province, People's Republic of China in 1995 and 1996, using direct DNA sequencing and PCR. For cases, samples of tumor and normal-appearing squamous esophageal tissue were snap-frozen in liquid nitrogen immediately after removal of the esophagus. Frozen tissue was ground to a powder and total DNA (nuclear and mitochondrial) was extracted using standard methods. Also, representative pieces of tumor tissue were fixed in formalin, embedded in paraffin, sectioned, and stained with H\&E for confirmation of diagnosis. Subjects with tumors without significant inflammation and sections that contained mostly tumor cells were selected to reduce contamination from inflammatory cell and normal cell mtDNA. From both cases and a healthy reference group of 23 healthy individuals, $10 \mathrm{ml}$ of venous blood was collected and total DNA was extracted using standard methods. The Institutional Review Boards of the Shanxi Cancer Hospital and the U.S. National Cancer Institute approved this study.

The mitochondrial control region from each sample was amplified by PCR (forward primer 5'-CTAATACACCAGTCTTGTAAACC-3'; reverse primer 5'-GGTGATGTGAGCCCGTCTAAAC-3') and sequenced with BigDye terminator chemistry (Applied Biosystems) and the ABI PRISM 377 genetic sequencer (Applera Corporation). Eight primers, four forward and four reverse (all primer sequences can be obtained from the corresponding author), were used to sequence the relatively short stretch to ensure high quality factors. The first set of four primers used spanned the CR. The second set of four primers were 
used to span the homopolymer region, which tends to be longer in Asian individuals and tends to cause more sequencing errors. DNA sequences were assembled using the STADEN Gap4 program.

To identify point mutations, insertions, and deletions in the CR of the tumor tissues, we compared each of the case subjects CR sequence from tumor DNA to their sequence from blood DNA. We ensured accurate comparisons by completing short tandem repeat analysis (STR) on all samples using ABIAmpFISTR Profiler Plus PCR STR multiplex assay on an ABI 310 genetic analyzer (Applera Corporation). Profiles were determined using Genescan 3.1.2 and Genotyper 2.5.

To assess the presence of the common deletion, we employed a modification of the method of Maximo [19]. Two pairs of forward and reverse PCR primers were designed such that one (Mitin2) produced a 271 bp amplicon from intact mitochondrial DNA in the region of cytochrome oxidase subunit III (Mitin2F 9500-9520; Mitin2R 9761-9742) and the other (Mitout2) produced a 5,190 bp amplicon spanning the region between ATPase 8 and NADH Dehydrogenase Subunit 5 in wild type mtDNA (Mitout2F 8370-8392; Mitout2R 1356013539). The Mitin2 amplification product, which should be present in all samples, was used as an amplification control. If the $4977 \mathrm{bp}$ common deletion was present, the Mitout2 primers were positioned such that a $213 \mathrm{bp}$ fragment was generated from the fusion product. Standard PCR conditions were used $\left(55^{\circ} \mathrm{C}\right.$ annealing) following the manufacturer's conditions (Supermix, Invitrogen). Products were examined following 35 cycles of PCR amplification by electrophoresis in $1.0 \%$ low melt agarose gels. The identities of the amplified products were confirmed through cloning the PCR products, sequencing the inserts, and comparing them to the appropriate mtDNA sequence.

\section{Results and Discussion}

We compared each of the CR sequences from blood of the healthy individuals and cases to the Revised Cambridge Reference Sequence (12) and found a total of 285 variants (polymorphisms) for the healthy group (median $=12$ variants per subject, range 9-17) and 243 variants for the case group (median $=11$, range $7-18$ ). The site and frequency of each novel variant or variant with a frequency $\geq$ 5 is reported in Table 1 . The number of variants was not different between the two groups (Wilcoxon rank-sum test, $P=0.33$ ). We aligned all $\mathrm{CR}$ sequences from the healthy individuals and determined a consensus sequence for the group of 23 individuals. Next, we compared each of the case CR sequences to this healthy consensus CR sequence. Because mtDNA sequences show distinct ethno-geographic patterns, we expected and found fewer variants in the comparison of our case sequences to this local control group (median $=9$, range $6-15$ ) than in the comparison to the Cambridge sequence. Analysis of this limited data set using a phylogenetic tree (AlignX module, Vector NTI Suite 7.0, Informax, Bethesda, MD) produced no distinct groupings of cases separate from the healthy subjects (data not shown).

To examine acquired mutations we compared the blood sequence from each individual to the tumor and adjacent normal CR sequences (Table 2). We found that $7 / 21$ $(33 \%)$ subjects had at least one acquired mutation. The $95 \%$ confidence interval around this proportion of 33\% was $17 \%-55 \%$ (logit transform). Of the 7 subjects with alterations, 3 showed a single change while 4 (19\% of the total) showed greater than one acquired mutation. The total numbers of acquired mutations for these four samples were $2,2,8$, and 16 . The 16 changes in a single subject represent a mutation frequency of $1.4 \%$ of the total sequenced bases. The $33 \%$ rate of mutation that we found is comparable to some of the findings for other solid tumors $[9,10]$, but is higher than a previous report for gastric cancer [20]. or one of two reports for ESCC [15]. In contrast, a recent analysis restricted to the two hypervariable regions of the D-loop found that 13/38 (34\%) ESCC tumors in a Japanese series had acquired mutations [16].

We detected a clustering of acquired changes in two areas of the CR (Figure 1A). First, 4 of the 7 subjects with alterations in their tumors had a change in the homopolymeric stretch of Cs that are assigned to position 309. This region accounts for $22 \%$ of detected mutations across a broad spectrum of tumors [21]. The homopolymer region was also a site with a large number of variants in the blood samples with $76 \%$ of ESCC cases and $96 \%$ of healthy individuals in our study having a polymorphism at this site. Second, hypervariable segment one (HVS 1) was a broader region that contained a concentration of alterations. HVS1, has previously been identified as a 'hotspot' for both germline and somatic mutations [22], but the functional significance of mutations in this region remains unknown.

For each of the cancer cases we also sequenced the CR in mtDNA isolated from adjacent normal squamous esophageal tissue. In most cases the normal esophageal tissue sequence matched that of the blood (Table 2) and in no case did we find sequence alterations that were restricted to the adjacent normal tissue. Of the seven subjects with CR alterations in their tumors, 3 had an adjacent normal tissue CR sequence identical to blood and 4 shared some of the mtDNA changes seen in the adjacent tumor. In total, $11 / 31(36 \%)$ of the CR alterations found in the tumor samples were also present in the adjacent normal tissue. 
Table I: Novel and high frequency mtDNA polymorphisms detected in Shanxi, China.

\begin{tabular}{|c|c|c|c|}
\hline Nucleotide Position & Base Change & Healthy Reference Samples $(n=23)$ & ESCC Case Samples $(n=21)$ \\
\hline 73 & A-G & 21 & 21 \\
\hline 150 & C-T & 10 & 4 \\
\hline 152 & $\mathrm{~T}-\mathrm{C}$ & 6 & 5 \\
\hline 179 & $\mathrm{~T}-\mathrm{C}^{*}$ & 1 & 0 \\
\hline 195 & $\mathrm{~T}-\mathrm{C}$ & 5 & 2 \\
\hline 249 & A del & 4 & 5 \\
\hline 263 & A-G & 21 & 21 \\
\hline 309 & $\mathrm{C}-\mathrm{CC} / \mathrm{CCC}$ & $16 / 6$ & $12 / 4$ \\
\hline $310-311$ & TC del* & 1 & 0 \\
\hline 315 & $\mathrm{C}-\mathrm{CC}$ & 19 & 21 \\
\hline 320 & $\mathrm{C}-\mathrm{T}^{*}$ & 2 & 0 \\
\hline 358 & $\mathrm{~A}-\mathrm{C}^{*}$ & 2 & 0 \\
\hline 368 & A-G* & 0 & I \\
\hline 489 & $\mathrm{~T}-\mathrm{C}$ & 12 & 14 \\
\hline $523-524$ & AC del* & 6 & 7 \\
\hline 548 & C-T* & 0 & I \\
\hline 574 & A-G* & 0 & I \\
\hline 16155 & $A-T^{*}$ & I & 0 \\
\hline 16163 & A-C* & 1 & 0 \\
\hline 16172 & $\mathrm{~T}-\mathrm{C}$ & 2 & 6 \\
\hline 16183 & $A-C$ & 6 & 5 \\
\hline 16223 & $C-T$ & 19 & 13 \\
\hline 16289 & A-C* & 0 & 1 \\
\hline 16298 & $\mathrm{~T}-\mathrm{C}$ & 4 & 5 \\
\hline 16362 & $\mathrm{~T}-\mathrm{C}$ & 9 & 7 \\
\hline 16519 & $\mathrm{~T}-\mathrm{C}$ & 12 & 9 \\
\hline 16524 & $\mathrm{~A}-\mathrm{T}^{*}$ & 0 & I \\
\hline
\end{tabular}

Novel polymorphisms (denoted by *) were those not reported in the Mitomap database as of $6 / 01 / 2003$. High frequency was defined as polymorphisms present in $\geq 5$ samples in either group. Nucleotide position was defined by the Cambridge reference sequence (GenBank NC 001807).

We found 8 instances of heteroplasmy when comparing blood and tumor CR sequences. A typical example of heteroplasmy is presented in Figure $1 \mathrm{~B}$ (from case 21 at position 16 164). In total, we saw 4 positions where heteroplasmy was present in the tumor but not in the blood and 4 positions where heteroplasmy was present in the blood but not in the tumor. Case 18 showed a heteroplasmy in the normal adjacent tissue that was intermediate between the normal blood sequence and the tumor sequence. Heteroplasmy of mitochondrial DNA mutations is typical, and several models have been developed to explain this phenomenon $[23,24]$.

Using a PCR assay, we investigated the presence or absence of the 4977 bp common deletion in each of the case DNA samples (Table 2). To control for the ability to PCR amplify mtDNA, a primer set (Mitin2) that amplified a 271 bp product within the common deletion region (cytochrome oxidase III) was used as an amplification control (Figure 1C). The common deletion was considered present if the Mitout2 primers produced a $213 \mathrm{bp}$ fusion product of the ATPase 8 and $\mathrm{NADH}$ subunit 5 genes. The common deletion was not detected in any of the case blood samples. In contrast, the common deletion was found in 19/20 (95\%, 95\% CI = 72\%-99\%) of the adjacent normal samples and in $17 / 19$ (89\%, 95\% CI = $66 \%-97 \%$ ) of the tumor samples examined. Since we were unsuccessful in amplifying Mitin2 in three samples, we could not assess the presence of the common deletion in those samples.

The 4977 bp common deletion has been reported in a wide range of tumors, stressed tissues, and even normal appearing tissue. Certain diseases of aging, such as ocular myopathy, are commonly associated with an increase in mtDNA mutations and these mutations are often found to be clustered to regions such as the common deletion. A detailed study of thyroid tumors demonstrated that $43 / 43$ (100\%) of Hürthle cell adenomas and carcinomas carried the common deletion, while $0-33 \%$ of the adjacent parenchyma carried the same change [25]. In our study we found that $89 \%$ of tumors and $95 \%$ of the adjacent normal tissue carried the deletion. Our attempt to select tumors with few normal cells does not preclude the possi- 
A

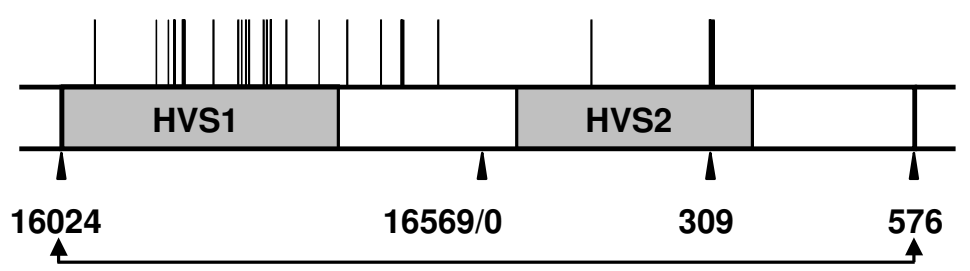

Mitochondrial DNA Control Region

B

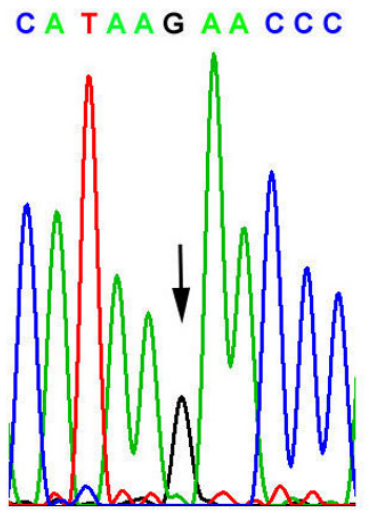

Adjacent Normal

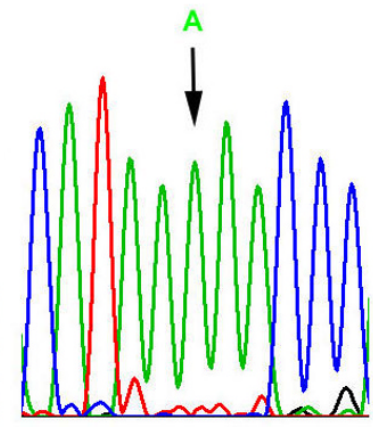

Tumor

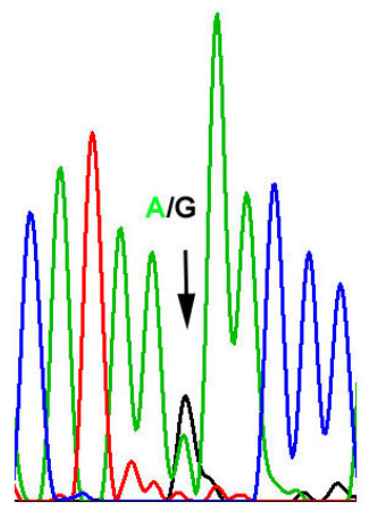

Blood

\section{C}
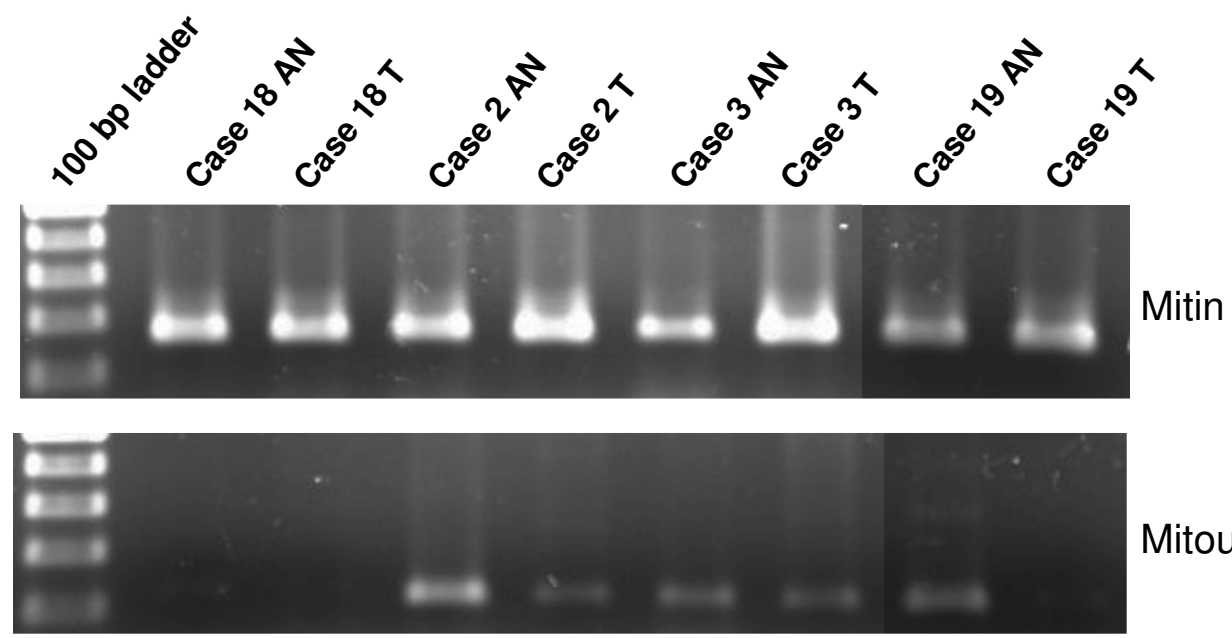

Mitout

\section{Figure I}

A, Location of mtDNA CR mutations in 21 esophageal cancer cases. 7/2I cases demonstrated CR mutations and a vertical bar indicates position within the region. In total, 31 mutations are indicated. Numbers below the bar refer to the standard mtDNA genome position numbering system. B, DNA sequencing electropherograms showing a heteroplasmy present at position 16164 in the blood DNA from case 2I. Although a preponderance of $G$ was found, a clear minority of the sequence was A as seen in the tumor DNA. C, I\% agarose gel from the Mitin2/ Mitout2 assay for the 4977 bp common deletion. AN refers to adjacent normal tissue and $\mathrm{T}$ to tumor tissue. A very faint band was present in the tumor sample from case 19. 
Table 2: mtDNA mutations detected in esophageal cancer cases in Shanxi, China.

\begin{tabular}{|c|c|c|c|c|c|c|c|c|}
\hline \multirow[t]{2}{*}{ Sample } & \multirow[t]{2}{*}{ Age } & \multirow[t]{2}{*}{ Sex } & \multicolumn{3}{|c|}{ Control Region Mutations } & \multicolumn{2}{|c|}{4977 bp 'Common' Deletion } & \multirow[t]{2}{*}{ Either Change } \\
\hline & & & $\begin{array}{l}\text { Nucleotide } \\
\text { Position }\end{array}$ & Change Blood $\rightarrow$ Tumor & $\begin{array}{l}\text { Adjacent Normal } \\
\text { Sequence }\end{array}$ & $\begin{array}{l}\text { Adjacent } \\
\text { Normal }\end{array}$ & Tumor & \\
\hline Case I & 56 & $\mathrm{~F}$ & & None & & Y & Y & Y \\
\hline Case 2 & 64 & $M$ & & None & & $Y$ & $Y$ & $Y$ \\
\hline Case 3 & 47 & $\mathrm{~F}$ & & None & & $Y$ & Y & $Y$ \\
\hline Case 4 & 55 & $M$ & & None & & $Y$ & $Y$ & Y \\
\hline Case 5 & 54 & $\mathrm{~F}$ & & None & & $Y$ & $Y$ & Y \\
\hline Case 6 & 59 & $M$ & & None & & $Y$ & $Y$ & Y \\
\hline Case 7 & 58 & $M$ & & None & & $Y$ & ND & $Y$ \\
\hline Case 8 & 53 & $M$ & & None & & $Y$ & $Y$ & $Y$ \\
\hline Case 9 & 66 & $M$ & & None & & $Y$ & $Y$ & $Y$ \\
\hline Case 10 & 50 & $\mathrm{~F}$ & & None & & $\mathrm{Y}$ & $Y$ & $Y$ \\
\hline Case II & 55 & $M$ & & None & & ND & ND & ND \\
\hline Case 12 & 62 & $F$ & & None & & $Y$ & $Y$ & $Y$ \\
\hline Case 13 & 49 & $M$ & & None & & $Y$ & $Y$ & $Y$ \\
\hline Case 14 & 59 & $\mathrm{~F}$ & & None & & $Y$ & $Y$ & $Y$ \\
\hline Case 15 & 65 & $M$ & 309 & del C & $\mathrm{C}$ & $Y$ & $Y$ & $Y$ \\
\hline Case 16 & 59 & $M$ & 16148 & $\mathrm{C} \rightarrow \mathrm{T} / \mathrm{c}$ & C & $Y$ & $Y$ & $Y$ \\
\hline Case 17 & 50 & $M$ & 309 & del C & $\mathrm{C}$ & $Y$ & $Y$ & $Y$ \\
\hline \multirow[t]{2}{*}{ Case 18} & 65 & $F$ & 309 & del C & $C$ & $N$ & $\mathrm{~N}$ & $Y$ \\
\hline & & & 16289 & $\mathrm{C} \rightarrow \mathrm{A}$ & $\mathrm{A} / \mathrm{c}$ & & & \\
\hline \multirow[t]{2}{*}{ Case 19} & 63 & $M$ & 16293 & $\mathrm{~A} \rightarrow \mathrm{G} / \mathrm{a}$ & A & $Y$ & $Y$ & $Y$ \\
\hline & & & 16319 & $\mathrm{G} / \mathrm{a} \rightarrow \mathrm{A}$ & $A$ & & & \\
\hline \multirow[t]{8}{*}{ Case 20} & 46 & $\mathrm{~F}$ & 16185 & $\mathrm{C} \rightarrow \mathrm{T}$ & $\mathrm{T}$ & $Y$ & $\mathrm{~N}$ & $Y$ \\
\hline & & & 16223 & $\mathrm{C} \rightarrow \mathrm{T}$ & $\mathrm{T}$ & & & \\
\hline & & & 16256 & $\mathrm{~T} \rightarrow \mathrm{C}$ & $C$ & & & \\
\hline & & & 16260 & $\mathrm{C} \rightarrow \mathrm{T}$ & $\mathrm{T}$ & & & \\
\hline & & & 16266 & $\mathrm{C} \rightarrow \mathrm{G} / \mathrm{c}$ & C & & & \\
\hline & & & 16270 & $\mathrm{~T} \rightarrow \mathrm{C}$ & C & & & \\
\hline & & & 16298 & $\mathrm{~T} \rightarrow \mathrm{C}$ & $\mathrm{C}$ & & & \\
\hline & & & 16399 & $\mathrm{G} \rightarrow \mathrm{A}$ & A & & & \\
\hline \multirow[t]{16}{*}{ Case 21} & 57 & $\mathrm{~F}$ & 150 & $\mathrm{~T} \rightarrow \mathrm{C}$ & $\mathrm{T}$ & $Y$ & $Y$ & $Y$ \\
\hline & & & 309 & del C & $\mathrm{C}$ & & & \\
\hline & & & 16067 & $\mathrm{~T} / \mathrm{c} \rightarrow \mathrm{C}$ & $\mathrm{T}$ & & & \\
\hline & & & 16164 & $\mathrm{G} / \mathrm{a} \rightarrow \mathrm{A}$ & G & & & \\
\hline & & & 16171 & $\mathrm{G} / \mathrm{a} \rightarrow \mathrm{A}$ & $\mathrm{G}$ & & & \\
\hline & & & 16172 & $\mathrm{C} \rightarrow \mathrm{T}$ & C & & & \\
\hline & & & 16182 & $C \rightarrow A$ & $\mathrm{C}$ & & & \\
\hline & & & 16183 & $\mathrm{C} \rightarrow \mathrm{A}$ & C & & & \\
\hline & & & 16184 & $\mathrm{C} \rightarrow \mathrm{T}$ & $\mathrm{C}$ & & & \\
\hline & & & 16298 & $\mathrm{~T} \rightarrow \mathrm{C} / \mathrm{t}$ & $\mathrm{T}$ & & & \\
\hline & & & 16362 & $\mathrm{C} \rightarrow \mathrm{T}$ & C & & & \\
\hline & & & 16443 & $\mathrm{~T} \rightarrow \mathrm{C}$ & $\mathrm{T}$ & & & \\
\hline & & & 16470 & $\mathrm{G} \rightarrow \mathrm{A}$ & G & & & \\
\hline & & & |647| & $\mathrm{G} \rightarrow \mathrm{A}$ & G & & & \\
\hline & & & 16473 & $\mathrm{G} \rightarrow \mathrm{A}$ & $\mathrm{G}$ & & & \\
\hline & & & 16519 & $\mathrm{C} \rightarrow \mathrm{T}$ & $\mathrm{C}$ & & & \\
\hline Cases (n & $=21)$ & & $7 / 21$ (33\%) & & & $19 / 20(95.0 \%)$ & $17 / 19$ (89.5\%) & $20 / 20(100 \%)$ \\
\hline
\end{tabular}

$\mathrm{Y}=\mathrm{Yes}, \mathrm{N}=\mathrm{No}, \mathrm{ND}=\mathrm{No}$ data, and $\mathrm{X} / \mathrm{x}$ indicates heteroplasmy with the predominant base as a capital letter.

bility that the presence of the common deletion in tumor samples was due to contamination from normal cells. The high prevalence of the common deletion in normal tissue is surprising and potentially useful as a risk marker, but this remains to be determined. We did not have tissue samples from persons with non-diseased esophagi for this study and we cannot conclude that the presence of the common deletion is limited to subjects with esophageal 
cancer. The cause of this ubiquitous deletion cannot be assessed in our current study, but a possible link between the mtDNA common deletion and DNA damage caused by exogenous agents was investigated in a study of oral cancer [26]. These investigators used a quantitative assay to show that people who chew betel quid, which contains multiple genotoxic substances, had an increased percentage of mtDNA carrying the common deletion in both tumor and histologically normal oral tissue.

\section{Conclusions}

In summary, CR mutations were present in 33\% of the tumors we examined. Although we have not formally tested the ability of CR mutations to serve as a cancer marker, this rate does not appear to be sufficient to warrant attempts to develop a CR mutation assay as an early detection method for ESCC. The incidence of the common deletion in the esophageal tissue of cancer patients was very high (95\%), making it a potential ESCC marker. The absence of the common deletion in the peripheral blood of the same patients suggests that exposure to carcinogens, aging, or both could be causing selectively higher mutation in the esophagus. Further study of this deletion in the esophageal tissue of healthy individuals and those with squamous dysplasia, the precursor lesion of ESCC, will help to determine whether it is directly associated with disease or is an age-related or exposure-related phenomenon in the esophageal tissue of members of this high risk population.

\section{List of abbreviations}

The abbreviations used are: bp; base pair; $\mathrm{CI}$, confidence interval; CR, control region; ESCC, esophageal squamous cell carcinoma; HVS, hypervariable segment; mtDNA, mitochondrial DNA.

\section{Competing interests}

None declared.

\section{Author contributions}

CCA designed and coordinated the study, tabulated and analyzed the results, and drafted the manuscript. $\mathrm{KH}$ designed and completed the common deletion assays and drafted the manuscript. AC and DA completed the CR sequencing and made the inter- and intra-subject comparisons. KM designed and supervised the CR sequencing protocols and drafted the manuscript. $\mathrm{NH}$ and Z-ZT collected the samples, isolated the DNA, and participated in drafting the manuscript. PRT and SMD oversaw study design, completion, and interpretation and drafted the manuscript.

\section{References}

I. Blot WJ, Li JY: Some considerations in the design of a nutrition intervention trial in Linxian, People's Republic of China. Natl Cancer Inst Monogr 1985, 69:29-34.
2. Hu N, Dawsey SM, Wu M, Taylor PR: Family history of oesophageal cancer in Shanxi Province, China. Eur J Cancer 1991, 27: I336.

3. Hu N, Dawsey SM, Wu M, Bonney GE, He LJ, Han XY, Fu M, Taylor PR: Familial aggregation of oesophageal cancer in Yangcheng County, Shanxi Province, China. Int J Epidemiol 1992, 2 I:877-882

4. Mark SD, Qiao YL, Dawsey SM, Wu YP, Katki H, Gunter EW, Fraumeni J.F.,Jr., Blot WJ, Dong ZW, Taylor PR: Prospective study of serum selenium levels and incident esophageal and gastric cancers. J Natl Cancer Inst 2000, 92: I753-I763.

5. Abnet CC, Y-L Qiao, Mark SD, Z-W Dong, Taylor PR, Dawsey S: Prospective study of tooth loss and incident esophageal and gastric cancers in China. Cancer Causes Control 200I, I 2:847-854.

6. Guo W, Blot WJ, Li JY, Taylor PR, Liu BQ, Wang W, Wu YP, Zheng $W$, Dawsey SM, Li B: A nested case-control study of oesophageal and stomach cancers in the Linxian nutrition intervention trial. Int J Epidemiol 1994, 23:444-450.

7. Sawyer DE, Van Houten B: Repair of DNA damage in mitochondria. Mutat Res 1999, 434:161-176.

8. Penta JS, Johnson FM, Wachsman JT, Copeland WC: Mitochondrial DNA in human malignancy. Mutat Res 200I, 488: I I9-I 33.

9. Fliss MS, Usadel H, Caballero OL, Wu L, Buta MR, Eleff SM, Jen J, Sidransky D: Facile detection of mitochondrial DNA mutations in tumors and bodily fluids. Science 2000, 287:2017-2019.

10. Parrella P, Xiao Y, Fliss M, Sanchez-Cespedes M, Mazzarelli P, Rinaldi M, Nicol T, Gabrielson E, Cuomo C, Cohen D, Pandit S, Spencer M, Rabitti C, Fazio VM, Sidransky D: Detection of mitochondrial DNA mutations in primary breast cancer and fine-needle aspirates. Cancer Res 2001, 6 1:7623-7626.

II. Liu VW, Shi HH, Cheung AN, Chiu PM, Leung TW, Nagley P, Wong LC, Ngan HY: High incidence of somatic mitochondrial DNA mutations in human ovarian carcinomas. Cancer Res 2001, 6 I:5998-600I.

12. Tan DJ, Bai RK, Wong LJ: Comprehensive scanning of somatic mitochondrial DNA mutations in breast cancer. Cancer Res 2002, 62:972-976.

13. Andrews RM, Kubacka I, Chinnery PF, Lightowlers RN, Turnbull DM, Howell N: Reanalysis and revision of the Cambridge reference sequence for human mitochondrial DNA. Nat Genet 1999 , 23:147.

14. Maximo V, Soares P, Seruca R, Rocha AS, Castro P, Sobrinho-Simoes $M$ : Microsatellite instability, mitochondrial DNA large deletions, and mitochondrial DNA mutations in gastric carcinoma. Genes Chromosomes Cancer 200I, 32:136-| 43.

15. Hibi K, Nakayama H, Yamazaki T, Takase T, Taguchi M, Kasai Y, Ito K, Akiyama S, Nakao A: Mitochondrial DNA alteration in esophageal cancer. Int J Cancer 200I, 92:319-32I.

16. Kumimoto $H$, Yamane $Y$, Nishimoto $Y$, Fukami $H$, Shinoda $M$, Hatooka S, Ishizaki K: Frequent somatic mutations of mitochondrial DNA in esophageal squamous cell carcinoma. Int J Cancer 2004, 108:228-23।.

17. Miyazono F, Schneider PM, Metzger R, Warnecke-Eberz U, Baldus SE, Dienes HP, Aikou T, Hoelscher AH: Mutations in the mitochondrial DNA D-Loop region occur frequently in adenocarcinoma in Barrett's esophagus. Oncogene 2002, 21 : 3780-3783.

18. Shaheen N, Ransohoff DF: Gastroesophageal reflux, barrett esophagus, and esophageal cancer: scientific review. JAMA 2002, 287:|972-198|.

19. Maximo V, Soares P, Seruca R, Sobrinho-Simoes M: Comments on: mutations in mitochondrial control region DNA in gastric tumours of Japanese patients, Tamura, et al. Eur J Cancer 1999, 35, 316-3 I9. Eur J Cancer 1999, 35:1407-1408.

20. Tamura G, Nishizuka S, Maesawa C, Suzuki Y, Iwaya T, Sakata K, Endoh Y, Motoyama T: Mutations in mitochondrial control region DNA in gastric tumours of Japanese patients. Eur J Cancer 1999, 35:316-319.

21. Sanchez-Cespedes M, Parrella P, Nomoto S, Cohen D, Xiao Y, Esteller M, Jeronimo C, Jordan RC, Nicol T, Koch WM, Schoenberg M, Mazzarelli P, Fazio VM, Sidransky D: Identification of a mononucleotide repeat as a major target for mitochondrial DNA alterations in human tumors. Cancer Res 2001, 61:7015-7019.

22. Stoneking $M$ : Hypervariable sites in the mtDNA control region are mutational hotspots. Am J Hum Genet 2000, 67:1029-1032. 
23. Polyak K, Li Y, Zhu H, Lengauer C, Willson JK, Markowitz SD, Trush MA, Kinzler KW, Vogelstein B: Somatic mutations of the mitochondrial genome in human colorectal tumours. Nat Genet 1998, 20:29|-293.

24. Coller HA, Khrapko K, Bodyak ND, Nekhaeva E, Herrero-jimenez P, Thilly WG: High frequency of homoplasmic mitochondrial DNA mutations in human tumors can be explained without selection. Nat Genet 200I, 28:147-150.

25. Maximo V, Soares P, Lima J, Cameselle-Teijeiro J, Sobrinho-Simoes M: Mitochondrial DNA somatic mutations (point mutations and large deletions) and mitochondrial DNA variants in human thyroid pathology: a study with emphasis on Hurthle cell tumors. Am J Pathol 2002, 160:1857-1865.

26. Lee HC, Yin PH, Yu TN, Chang YD, Hsu WC, Kao SY, Chi CW, Liu TY, Wei YH: Accumulation of mitochondrial DNA deletions in human oral tissues -- effects of betel quid chewing and oral cancer. Mutat Res 200I, 493:67-74.

\section{Pre-publication history}

The pre-publication history for this paper can be accessed here:

http://www.biomedcentral.com/1471-2407/4/30/prepub

Publish with Biomed Central and every scientist can read your work free of charge

"BioMed Central will be the most significant development for disseminating the results of biomedical research in our lifetime. "

Sir Paul Nurse, Cancer Research UK

Your research papers will be:

- available free of charge to the entire biomedical community

- peer reviewed and published immediately upon acceptance

- cited in PubMed and archived on PubMed Central

- yours - you keep the copyright 